\title{
Modern imaging techniques in intra-abdominal hypertension and abdominal compartment syndrome: a bench to bedside overview
}

\author{
Gavin Sugrue ${ }^{1}$, Manu L.N.G. Malbrain ${ }^{2-4}$, Bruno Pereira ${ }^{5}$, Robert Wise ${ }^{6}$, Michael Sugrue ${ }^{7}$ \\ 'Department of Radiology, Mater Misericordiae University Hospital, Dublin, Ireland \\ ${ }^{2}$ Department of Intensive Care and High Care Burn Unit, Ziekenhuis Netwerk Antwerpen, ZNA Stuivenberg, \\ Antwerp, Belgium \\ ${ }^{3}$ Department of Intensive Care, University Hospital Brussel (UZ Brussel), Jette, Belgium \\ ${ }^{4}$ Faculty of Medicine, the Free University of Brussels (VUB) \\ ${ }^{5}$ Associate Professor of Surgery Trauma/Acute Care Surgery \& Surgical Critical Care \\ University of Campinas, Brazil \\ ${ }^{6} \mathrm{Head}$ Clinical Unit, Critical Care, Edendale Hospital, Pietermaritzburg, South Africa. Discipline of Anaesthe- \\ siology and Critical Care, School of Clinical Medicine, University of KwaZulu-Natal, Durban, South Africa \\ ${ }^{7}$ Department of Surgery, Donegal Clinical Research Academy, Letterkenny University Hospital, Donegal, \\ Ireland
}

\begin{abstract}
Intra-abdominal hypertension (IAH) is common in critically ill patients. Diagnosis is based on measurement of intraabdominal pressure, most commonly via the bladder. Modern imaging techniques with plain radiographs, computed tomography and magnetic resonance can help establish the diagnosis and also guide treatment. In 2013 the Abdominal Compartment Society (WSACS) published updated consensus definitions and recommendations for management of IAH and abdominal compartment syndrome (ACS). This review will give a concise overview of the important role radiographic imaging plays within these management guidelines.
\end{abstract}

Anaesthesiology Intensive Therapy 2018, vol. 50, no 3, 234-242

Key words: abdominal pressure; abdominal compartment syndrome; intra-abdominal hypertension; radiology, imaging, computed tomography; radiology, imaging, magnetic resonance

Intra-abdominal hypertension (IAH) is defined as a sustained increase in intra-abdominal pressure (IAP) equal to, or above $12 \mathrm{~mm} \mathrm{Hg}$. Abdominal compartment syndrome (ACS) is a clinical diagnosis based on IAP above $20 \mathrm{~mm}$ Hg with new organ failure [1]. The IAP is usually measured via the surrogate intravesical pressure via a Foley catheter. This reading is taken with the patient in a complete supine position with the zero reference at the level where the midaxillary line crosses the iliac crest, ensuring that abdominal contractions are absent. Radiology plays an increasingly important role in the management of patients with IAH/ACS. However, with the exception of percutaneous drainage of fluid collections, the comprehensive 2013 WSACS guidelines relating to ACS do not outline specific guidelines or consensus statements regarding radiological assessment and/or management of patients with IAH and ACS.

Ultrasound is a key point-of-care tool in the assessment of patients with IAH and ACS [2,3], and consequently other imaging modalities are often overlooked. This paper reviews the indications and key imaging findings in $\mathrm{IAH}$ and ACS with conventional imaging methods including computed tomography $(\mathrm{CT})$, magnetic resonance imaging (MRI), plain radiography, and also some novel imaging techniques. 


\section{COMPUTED TOMOGRAPHY}

There are no specific guidelines or consensus statements to date regarding the use of $\mathrm{CT}$ in the assessment or management of patients with IAH and ACS. Only a few small studies have identified characteristic $C T$ imaging features of IAH and ACS [4-8]. Key to ACS management is acknowledging that $\mathrm{IAH}$ is secondary to underlying pathology, frequently systemic inflammatory response syndrome (SIRS), bleeding, or fluid extravasation [9]. Radiological imaging aims to compliment the clinical decision process, facilitating a rapid diagnosis (especially when clinical signs and symptoms are dubious) and early instigation of treatment options.

The etiology of raised IAP in patients with Grade 3 (IAP > $20 \mathrm{~mm} \mathrm{Hg}$ ) or 4 (IAP > $25 \mathrm{~mm} \mathrm{Hg}$ ) IAH is frequently identified on abdominal CT. The development of such high IAP may occur as a consequence of missing an early IAH diagnosis, possibly due to failure of attending physicians to implement early IAH measurement. Computed tomography imaging protocols vary between institutions and the suspected aetiology of IAH and ACS. An abdominal CT protocol includes at least a dual-phase intravenous contrast enhanced CT study (arterial and porto-venous phases) with axial, sagittal and coronal reformats. Modern CT scanning technology allows for rapid acquisition of head, abdominal and thoracic imaging at increasingly lower doses, with doses as low as $1.2 \mathrm{mSV}$ now possible for abdominal CT [10]. Computed tomography thus serves as a useful tool for rapid multiorgan radiological assessment of patients with suspected or known IAH and ACS. Challenges with CT include a delay in identifying the need for $\mathrm{CT}$ in the first instance, and secondly failing to act on the results in a timely manner [11]. A list with indications for CT in suspected $\mathrm{IAH}$ and ACS are outlined in Table 1.

\section{IDENTIFICATION OF RISK FACTORS FOR DEVELOPING IAH AND ACS}

Computed tomography can identify well-recognised risk factors for the development of IAH and ACS 1 (Table 2) and thus be used as a screening tool in patients at risk. Findings must be interpreted in conjunction with patients' clinical examination, point of care ultrasound findings, biochemical laboratory results and physiological profile. Radiologists in particular need to be aware of risk factors for developing $\mathrm{IAH}$ and $\mathrm{ACS}$ at the time of CT interpretation. Importantly, $C T$ is limited to identifying anatomical and structural risk factors (for example acute pancreatitis, acute haemorrhage) rather than biochemical and physiological risk factors such as acidosis, coagulopathy and hypothermia. Once key risk factors are identified, for example severe pancreatitis, the
Table 1. Indications for $\mathrm{CT}$ in suspected or known IAH or ACS Identify risk factors for developing IAH and ACS Identify the cause of IAH and ACS and categorise as primary or secondary ACS

Identify characteristic CT features associated with IAH and ACS Early recognition of multi-organ complications of IAH and ACS Identify intraperitoneal fluid for percutaneous drainage, paracentesis or guide interventional radiology procedures.

Sequential imaging to monitor response to medical and/or surgical management of IAH/ACS

Clearly identify site of sepsis to aid in source control and reduce risk of tertiary peritonitis

Pre-operative assessment of the anterior abdominal wall musculature and extent of abdominal wall defect in patients undergoing delayed reconstruction following an open abdomen

Table 2. Correlation between risk factors for IAH or ACS and CT imaging

\begin{tabular}{|c|c|}
\hline $\begin{array}{l}\text { Risk factors for } \\
\text { IAH and ACS }\end{array}$ & CT imaging features \\
\hline $\begin{array}{l}\text { Increased } \\
\text { intra-luminal } \\
\text { contents }\end{array}$ & $\begin{array}{l}\text { Gastric distension } \\
\text { Distended loops of small bowel or large bowel } \\
\text { Small or large bowel obstruction }\end{array}$ \\
\hline $\begin{array}{l}\text { Increased intra- } \\
\text { abdominal } \\
\text { contents }\end{array}$ & $\begin{array}{l}\text { Acute pancreatitis/peripancreatic collection and } \\
\text { necrosis } \\
\text { Haemoperitoneum } \pm \text { active abdominal bleeding } \\
\text { Intra-peritoneal fluid collections } \\
\text { Intra-abdominal free air } \\
\text { Intra-abdominal mass } \\
\text { Abdominal aortic aneurysm } \\
\text { Cirrhosis } \\
\text { Hypersplenism (e.g. in chronic myeloid leukemia) }\end{array}$ \\
\hline $\begin{array}{l}\text { Capillary } \\
\text { leak/fluid } \\
\text { resuscitation }\end{array}$ & $\begin{array}{l}\text { Pulmonary oedema and pleural effusion } \\
\text { Small or large bowel wall oedema } \\
\text { Ascites } \\
\text { Subcutaneous oedema }\end{array}$ \\
\hline $\begin{array}{l}\text { Reduced } \\
\text { abdominal wall } \\
\text { compliance }\end{array}$ & $\begin{array}{l}\text { Recent evidence of abdominal wall surgery } \\
\text { Major abdominal trauma } \\
\text { Burns with circular eschars }\end{array}$ \\
\hline Other findings & $\begin{array}{l}\text { Increased BMI/Obesity } \\
\text { Visceral fat vs subcutaneous fat } \\
\text { Apple (round) vs peer (ellipse) shape } \\
\text { Mechanical ventilation } \\
\text { Sepsis } \\
\text { Large incision abdominal wall hernia }\end{array}$ \\
\hline
\end{tabular}

challenge remains for clinicians to decide the optimum time to intervene [12].

\section{CATEGORISATION OF PRIMARY VERSUS SECONDARY ACS}

Computed tomography can be utilised to identify a primary or secondary cause of IAH and ACS. For example, abdominal $\mathrm{CT}$ is pivotal in the assessment of suspected intra-abdominal haemorrhage in trauma [13]. In this setting, CT angiography can identify the possible site of bleeding and a target for interventional radiology or surgical intervention (Fig. 1). 

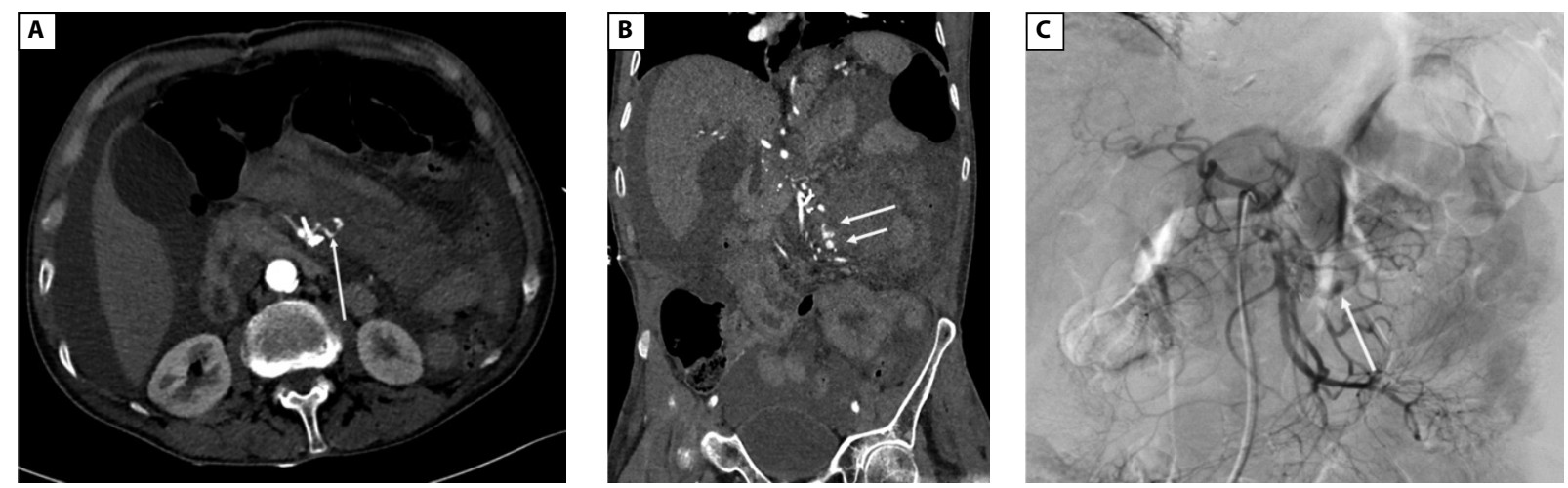

Figure 1. 38-year-old male patient with primary ACS (IAP $28 \mathrm{~mm} \mathrm{Hg}$ ) secondary to blunt abdominal trauma. $\mathbf{A}-$ axial arterial phase CT show active extravasation adjacent to the SMA (yellow arrow) consistent with post-traumatic SMA dissection; B — coronal contrast enhanced CT demonstrates large volume intra-peritoneal and retro-peritoneal high density fluid consistent with hemoperitoneum. Multiple sites of arterial extravasation (black arrows) are seen adjacent to the SMA; C - selective catheter angiogram of the SMA demonstrates a small vascular blush (white arrow) correlating the contrast extravasation identified on CT

Table 3. Spectrum of CT imaging findings in IAH and ACS

Narrowing of upper intra-hepatic IVC (defined as IVC diameter

$<3 \mathrm{~mm}$ on two or three contiguous CT images)

Round belly sign (RBS)

Direct renal compression or displacement

Small or large bowel wall thickening with contrast enhancement (BWTE)

Compression or displacement of solid abdominal viscera

Bilateral inguinal herniation

Elevation of the diaphragm

Thoracic disease at the lungs bases

Ascites or haemoperitoneum

Pneumoperitoneum

\section{IDENTIFICATION OF CHARACTERISTIC CT FEATURES ASSOCIATED WITH IAH AND ACS}

Characteristic abdominal CT findings in patients with $\mathrm{IAH}$ and ACS have been assessed in two studies [2,3] and case report/series [4-6] (Table 3). Pickhardt et al. [5] were the first to describe the round belly sign (RBS), defined as an increased ratio of anteroposterior: transverse diameter (ratio $>0.80$ ) [5].This radiological sign is easy to calculate and is measured where the left renal vein crosses the aorta with exclusion of subcutaneous fat (Fig. 2). The largest study by Al-Bahrani et al. [4] assessed the validity of several signs (Table 3) in 48 CT scans [2]. They concluded that only the RBS and bowel wall thickening with enhancement (BWTE) were observed more frequently with relatively high specificity in patients with IAH. The RBS was identified in $78 \%$ of patients with IAH and in only $20 \%$ of those with IAP $<12 \mathrm{~mm} \mathrm{Hg}$ $(P<0.001)$. BWTE was observed in 39\% with IAH and 3\% of patients with IAP $<12 \mathrm{~mm} \mathrm{Hg}(P=0.003)$. Furthermore, both RBS and BWTE signs were independently predictive of
IAH, but only BWTE was significantly associated with ACS. Interestingly, Al-Bahrani et al. [4]. observed poor correlation between the two radiologists when identifying certain $\mathrm{CT}$ features, in particular narrowing of the upper intrahepatic inferior vena cava, IVC $(r=0.067, P=0.653)$ and the compression or displacement of solid abdominal viscera $(r=0.239$, $P=0.101$ ). A smaller study of 4 patients by Pickhardt et al. [3], all with IAP > $35 \mathrm{~mm} \mathrm{Hg}$ showed significant correlation between RBS and ACS, with sensitivity and specificity of $100 \%$ and $94 \%$ respectively. Both these studies are limited by small patient numbers and larger prospective studies are required.

The etiology of abnormal BWTE patterns identified on $C T$ in patients in IAH and ACS is multifactorial, with well described concomitant changes on a pathophysiological level. Intraabdominal hypertension causes a reduction in mesenteric and hepatic vessel flow [14], which can cause bowel ischemia and hepatic dysfunction [15]. For example, animal studies have shown that an IAP of 20 $\mathrm{mm} \mathrm{Hg}$ reduces flow in the mesenteric and hepatic arteries and the intestinal mucosa by $73 \%, 55 \%$ and $61 \%$ respectively $[16,17]$. In conjunction with this arterial insufficiency, $\mathrm{IAH}$ and ACS results in mesenteric venous compression, increased bowel wall permeability and bacterial translocation [18]. It is a culmination of these processes, termed acute intestinal distress syndrome [19], that best accounts for abnormal BWTE in IAH and ACS.

\section{EARLY RECOGNITION OF MULTI-ORGAN COMPLICATIONS OF IAH AND ACS}

Computed tomography can be used to assess for nongastrointestinal multi-organ complications of IAH and ACS.

- Respiratory: Increased IAP results in the upward displacement of the diaphragm, causing dorsobasal compressive pulmonary atelectasis [20]. Atelectasis mani- 


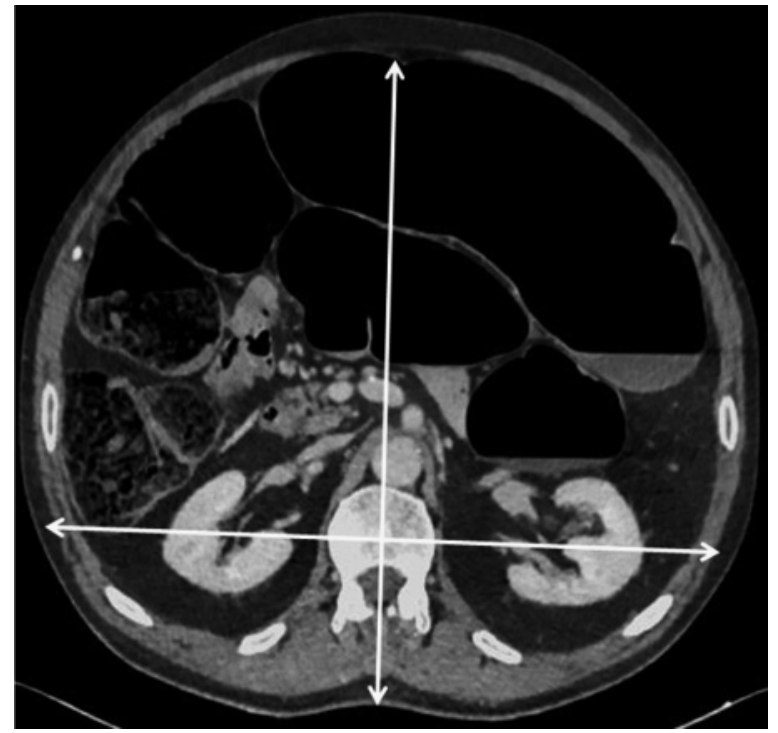

Figure 2. The round belly sign (RBS). An annotated CT image demonstrating the round belly sign. This sign is the ratio of the antero-posterior:transverse dimension of the abdomen. It is measured where the left renal vein crosses the aorta with exclusion of the subcutaneous abdominal wall fat. The antero-posterior:transverse diameter $=0.86$ in this example

fests on CT as linear regions of bibasal opacification. If large enough, atelectasis may demonstrate crowding of pulmonary vessels, air bronchograms and displacement of the interlobar fissures (Figs 3 and 4) [21-23]. Elevated IAP may also increase extravascular lung water and result in pulmonary edema [24], characterised on CT by interlobular septal thickening, diffuse ground-glass opacities (that are most pronounced dependently), and pleural effusions [25].

- Renal: Renal dysfunction is well described in IAH and ACS [26]. Computed tomography may identify flattening of the renal veins, observed in 14/21 (66.7\%) patients on CT with IAH/ACS [4]. with an accompanying elevation of renal vein pressures, hypothesised as a cause of acute renal failure early in the course if IAH and ACS [21]. Dedicated renal ultrasound, however, is the gold standard for assessment of renal resistive indices, which are often elevated in IAH and ACS [27].

- Neurological: Raised IAP is directly related to raised ICP, and decreased CPP [28], however, no neuroimaging has correlated these physiological changes to date. Advanced CT and MR perfusion techniques can now assess cerebral blood flow [29], and may be of interest in future studies of patients with IAH and ACS.

\section{ESTIMATION OF INTRA-ABDOMINAL VOLUME AND COMPLIANCE}

Abdominal compliance is a measure of the ease of abdominal expansion and is determined by the elasticity of the abdominal wall and diaphragm [30]. Abdominal CT can provide rapid and accurate assessment of the distribution of abdominal fat through subjective or objective means [31]. Firstly, abdominal CT can be used to quantify abdominal fat as android (mainly visceral and sphere shaped) or gynoid (mainly subcutaneous and ellipse shaped) [32]. Patients with android fat distribution have reduced capacity to accommodate an increase in intraabdominal volume. In comparison, patients with gynoid fat distribution [33, 34], have an improved stretching capacity and abdominal wall compliance. This may have potential in identifying patients that are more likely to progress from intra-abdominal hypertension to ACS. Computed tomography has also been used to explore the relationship between intra-abdominal volume and intra-abdominal pressure. For example, Mulier et al. [35] demonstrated abdominal wall elongation plays a more significant role than lateral wall deformation in the setting of elevated IAP. This was demonstrated by the laparoscopic insufflation of air at the time of CT colongraphy [35]. Likewise, rectal insufflation of air at the time of $\mathrm{CT}$ confirms the key role the diaphragm and anterior abdominal wall plays in adapting to elevated IAP [36]. The cranial ascent of the diaphragm in IAH and ACS is well illustrated on thoracic and abdominal CT imaging (Figs 3,4), with this elevation of the diaphragm increasing non-aerated lung volumes. Zhou et al has demonstrated that lung volumes in patients with elevated raised IAP, calculated on thoracic CT imaging, return back to normal control values after surgical intervention (decompressive laparotomy) [37]. Furthermore, advances in radiological imaging techniques now allow for assessment intraabdominal volume. For example, Hounsfield Units (HU), which is the scale used for tissue density in CT imaging, can be used to estimate the volume of solid organs [38]

\section{IDENTIFICATION OF FREE INTRAPERITONEAL FLUID FOR PERCUTANEOUS DRAINAGE, PARACENTESIS OR GUIDANCE OF INTERVENTIONAL RADIOLOGY PROCEDURES}

Patients with IAH and ACS often have co-existent pleural effusions or intra-abdominal free fluid collections. Computed tomography and point-of-care ultrasound (POCUS) allow for rapid and accurate identification of pleural and intra-abdominal fluid, which can be subsequently targeted for sampling or percutaneous drainage (PCD). The most recent 2013 WSACS recommendations regarding PCD include [1]:

1. Use PCD to remove fluid (in the setting of obvious intraperitoneal fluid) in those with IAH and ACS when this is technically possible compared to doing nothing [Grade 2C]. 

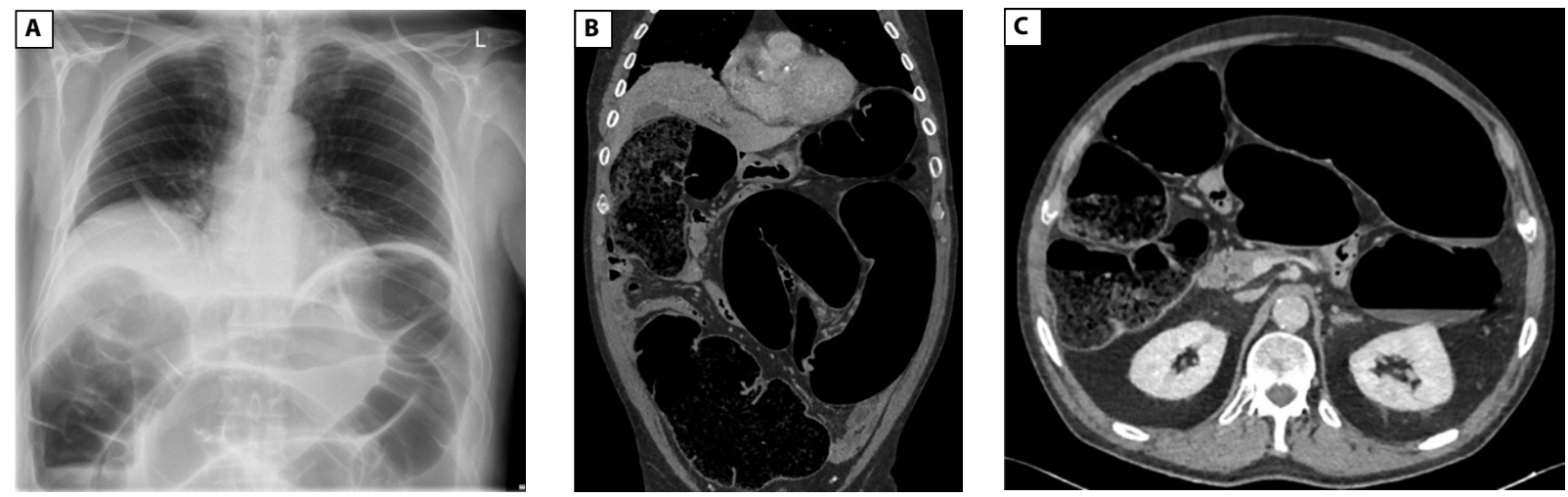

Figure 3. 75-year-old male with IAH $(25 \mathrm{~mm} \mathrm{Hg})$ secondary to a sigmoid volvulus. A — chest x-ray demonstrates grossly dilated loops of large bowel. There is associated elevation of the hemi-diaphragms and mild bi-basal atelectasis; $\mathbf{B}$ - coronal contrast enhanced CT shows dilated loops of large bowel secondary to a sigmoid volvulus. The cecum measures $13 \mathrm{~cm}$ with no evidence of perforation; $\mathbf{C}-$ axial contrast enhanced CT shows a distended loops of large bowel within a distended abdominal cavity. The antero-posterior:transverse diameter is calculated at 0.81 , consistent with the round belly sign
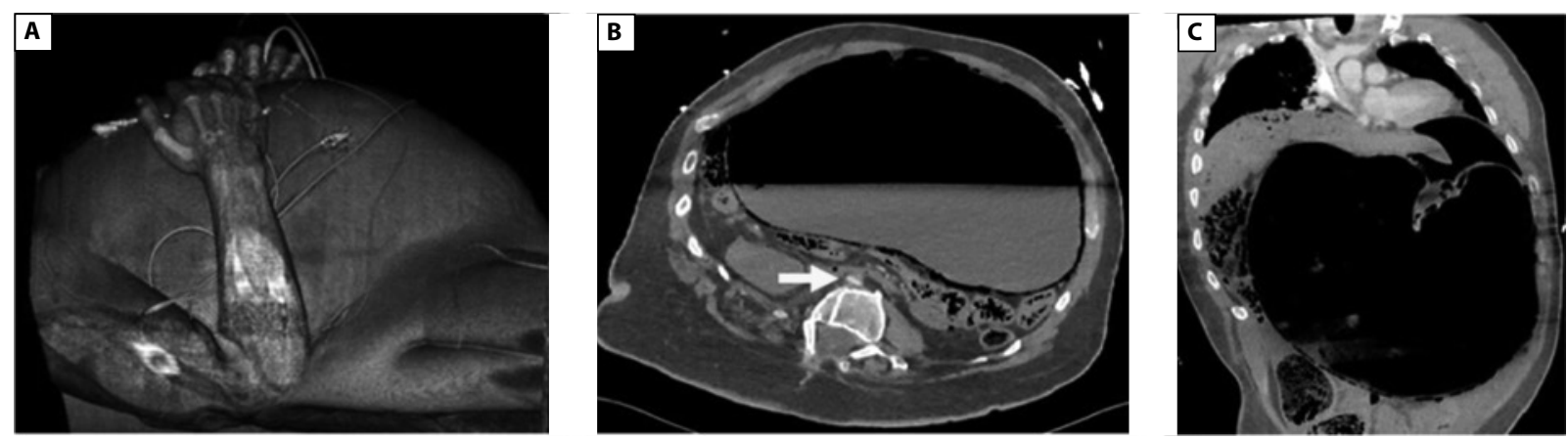

Figure 4. 44-year-old with ACS (IAP $32 \mathrm{~mm} \mathrm{Hg}$ ) secondary to a gastric volvulus. A — surface rendered 3D-CT image shows a distended and tense abdomen; B - axial contrast enhanced CT identifies a grossly dilated stomach filled with air and fluid secondary to a large gastric volvulus. The distended stomach causes near complete compression of the aorta (black arrow). The IVC is not identified as it is completely effaced. The round belly sign is present (0.82); C - coronal contrast enhanced CT demonstrates a gastric volvulus with associated significant abdominal distention. Pneumatosis within the stomach wall and intra-hepatic porto-venous gas is consistent with gastric ischemia. There is resultant elevation of both hemi-diaphragms and significantly reduced lung volumes

2. Use PCD to remove fluid (in the setting of obvious intraperitoneal fluid) in those with IAH and ACS when this is technically possible compared to immediate decompressive laparotomy as this may alleviate the need for decompressive laparotomy [Grade 2D].

Percutaneous drainage of intra-abdominal collections is a minimally invasive technique to reduce IAP, and may avoid the need for open surgical decompression [39]. Cheatham et al. [39] described failure of PCD as failure to drain at least $1000 \mathrm{~mL}$ of fluid, and a post-decompression change in IAP of at least $9 \mathrm{~mm} \mathrm{Hg}$ within the first 4 hours post $P C D$. As opposed to CT guidance, ultrasound guided drainage is a non-ionising and portable alternative for bedside thoracic or abdominal fluid drainage in critically ill patients. Percutaneous guided CT drainage is typically reserved for patients with complex or loculated fluid collections. Cross-sectional CT images acquired the time of drain insertion improves visualisation of adjacent vascular and visceral structures. To date, thresholds and specific indications for PCD of fluid collections in IAH and ACS are not well established. Stratifying patients that will benefit from PCD rather than immediate surgical decompression continues to pose a challenge, and further studies are required [4].

\section{LIMITATIONS OF CT}

The role of $C T$ in IAH and ACS is limited by the paucity of well conducted prospective studies evaluating its role in the assessment, management and intervention of IAH and ACS. Further limitations of CT include the need for inter and intra-hospital transfer of critically ill patients to the radiology department, which carries challenges and risk of complications [41]. The link between malignancy and ionizing radiation exposure [42] is a notable consideration with multiple CT investigations. Finally, it is now becoming evident that initial concerns regarding intravenous contrast 
and resultant acute kidney injury, termed contrast induced nephropathy (CIN), were overestimated [43]. The largest and most recent study to date was unable to established between IV contrast and CIN [44].

Finally, judicious use and clinical interpretation of abdominal $C T$ imaging findings in patients with IAH and ACS is essential. For example, in the setting of profound hypotension secondary to fulminant ACS, urgent decompressive laparotomy is recommended [1]. Surgery should not be delayed for CT imaging. In addition, patients with recurrent ACS, whom already have an abdominal incision, may require immediate bedside decompression in the intensive care unit (ICU). In both these clinical scenarios, it is important to emphasize that CT is of no immediate value, especially when urgent surgical decompression is required to achieve an immediate reduction in IAP [45]. Likewise, mesenteric ischemia in the setting of IAH and ACS can be difficult to diagnose with only $\mathrm{CT}$ imaging findings. Imaging features, such as pneumatosis intestinalis, can be associated with benign and life threatening conditions [46]. Therefore correlation with validated clinical parameters such as lactic acidosis, abdominal tenderness and tachycardia [47] is required to overcome these limitations, and more accurately predict ischemic bowel at surgery.

\section{MRI}

Magnetic resonance imaging plays a very limited role in the evaluation of patients with IAH and ACS. This is primarily due to the long MR image acquisition time (often $>30$ minutes) needed to complete a study. Furthermore, difficulties often arise with MR compatible equipment, monitoring patients throughout the duration of the MRI scan, and intra- and inter-hospital transfers of critically ill patients. Alternatively, point of care ultrasound performed at the bedside or $\mathrm{CT}$ can be used to acquire the same information, if not more information, than an MR study. Even when image acquisition is successful in critically ill patients, images are often degraded by motion and breathing artefacts, potentially rendering the MR non-diagnostic. Magnetic resonance imaging may have a unique role in pregnancy by avoiding foetal radiation associated with CT studies, however, the risk versus the benefit in critically ill patients will require considered deliberation.

\section{PLAIN RADIOGRAPHS CHEST RADIOGRAPHS}

The indication for chest radiography in ICU patients is controversial [48], with no data to support its routine use [49]. Chest radiographs can show a wide spectrum of findings including atelectasis, pleural effusions, lobar collapse and acute respiratory distress syndrome (ARDS). ARDS may mani- fest itself as bilateral airspace disease, which is not fully explained by effusions, lobar or lung collapse, or nodules [50]. The presence of ARDS, although observed in IAH and ACS, is not specific to patients with raised IAP. The presence of ARDS, although observed in IAH/ACS, are not specific to patients with IAH/ACS. A tension pneumothorax has also been described as a cause for IAH/ACS [51-53].

\section{ABDOMINAL RADIOGRAPHS}

Abdominal radiographs are of little of value in patients with IAH and ACS. An exception may include the diagnosis of suspected bowel obstruction with radiographs demonstrating good sensitivity ( $84 \%$ versus $82 \%$ for small and large bowel obstruction respectively) and specificity (72\% versus $83 \%$ respectively) $[54,55]$. However, the majority will require $\mathrm{CT}$ assessment for a transition point, bowel viability and complications (perforation, intra-abdominal fluid collections) [56].

\section{NOVEL IMAGING TECHNIQUES — IMAGING OF THE MICROCIRCULATION}

The microcirculation consists of a network of small blood vessels ( $<100$ micrometers in diameter) that delivers oxygen to tissue cells. Early studies demonstrated that flow within the micro-circulation is significantly altered in patients with severe sepsis, and is associated with poor outcomes [57]. While efforts are made to correct macrohemodynamic parameters with fluids and/or vasoactive agents, it is felt that the microcirculation may in fact remain hypoperfused [58]. Thus, there is a growing trend to utilise microscopic camera technology to visualise the microcirculation in critically ill patients [59]. Modern imaging techniques using sidestream dark-field (SDF) and incident dark-field (IDF) imaging can be performed at the bedside. Several microcirculatory parameters have been described [60], for example, the microvascular flow index (MFI), which is a semi quantitative measure of perfusion quality. It is calculated by dividing an image into four quadrants and the predominant type of flow (absent $=0$, intermittent $=1$, sluggish $=2$, and normal $=3$ ) is assessed . While this technology is not widely available, advances in camera image quality and imaging analysis technology will allow these techniques to become more widely available.

\section{FUTURE AREAS OF INTEREST}

Advances in CT technology may allow for automated techniques to calculate intra-abdominal volume. Currently portable CT technology is utilised for head imaging in Neurosurgical centers [61]. Further advances in CT technology may allow for portable abdominal CT to 


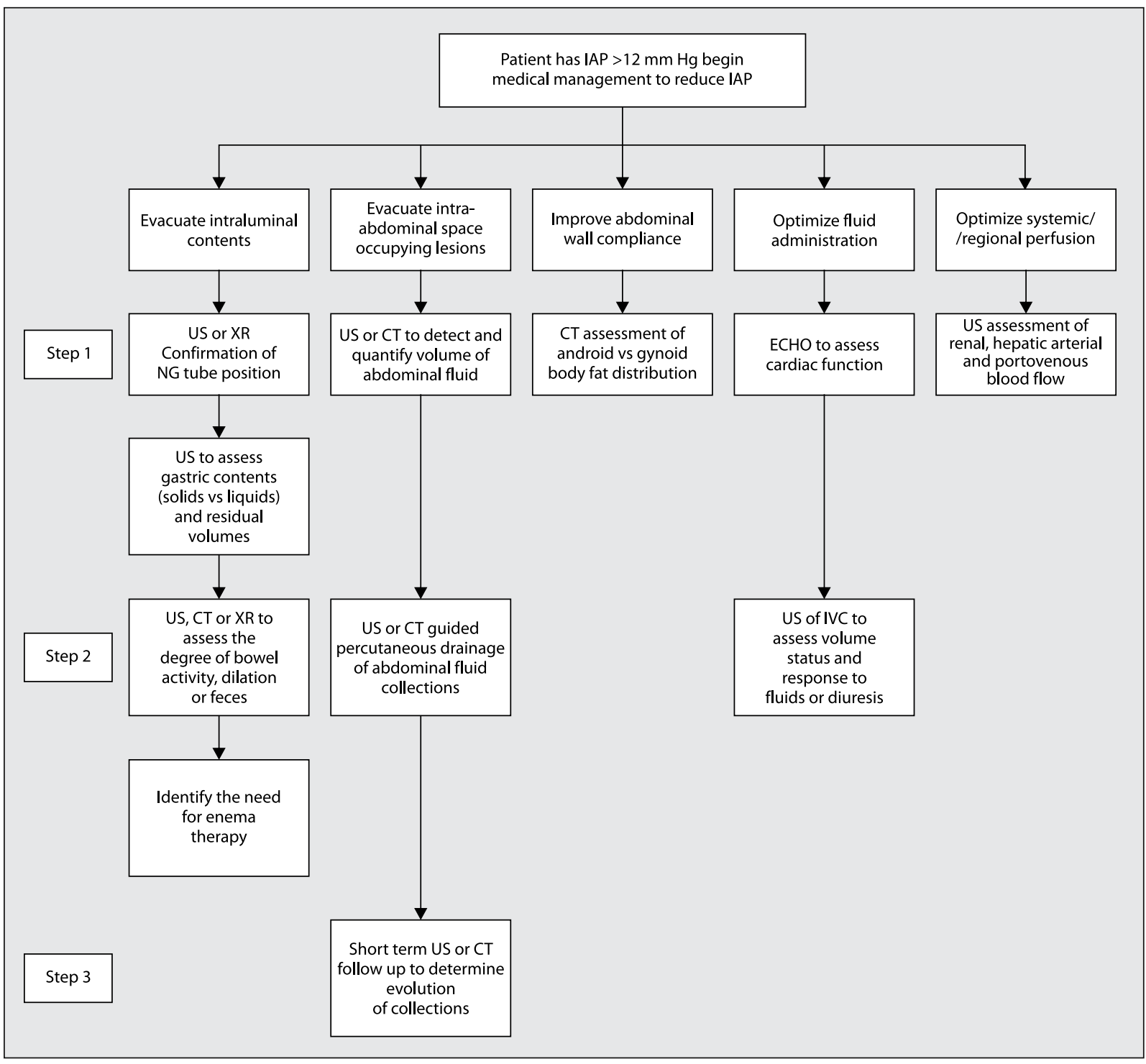

Figure 5. Role for radiology within the WSACS management algorithm

obviate the need for transporting critically ill patients. Prospective studies are required to determine the role CT has in the evaluating the relationship between intraabdominal volume and intra-abdominal pressure. The potential for CT to combine volumetric measures, including intra-vascular volume and dynamic perfusion status, to include dynamic compliance data would be very exciting. Also, clinicians caring for critically ill patients need to be aware of the pointers to both IAH and ACS and recognise the evolving initiators of intra-abdominal hypertension and its adverse effects. Likewise, there is a need for continued education of radiologists in understanding the key principles of the abdominal compartment syndrome, highlighting their role in management of patients with IAH and ACS.

\section{CONCLUSIONS}

Multi-modal radiological evaluation serves as a complementary tool in the diagnosis, management and treatment of patients with suspected or known IAH and ACS. The utility of point-of-care ultrasound and CT imaging in particular, emphasises the need for a multidisciplinary diagnostic and therapeutic approach for patients with IAH and ACS for which radiology will play an increasingly vital role. Early and appropriate imaging of patients with IAH or evolving ACS aims to guide management, prevent complications and reduce mortality.

\section{ACKNOWLEDGEMENTS}

Manu L.N.G. Malbrain is founding President of WSACS (The Abdominal Compartment Society) and current Treas- 
urer, he is also member of the medical advisory Board of Pulsion Medical Systems (part of Maquet Getinge group) and consults for ConvaTec, Acelity, Spiegelberg and Holtech Medical. He is co-founder of the International Fluid Academy (IFA). This article is endorsed by the IFA. The mission statement of the IFA is to foster education, promote research on fluid management and hemodynamic monitoring, and thereby improve survival of critically ill by bringing together physicians, nurses, and others from throughout the world and from a variety of clinical disciplines. The IFA is integrated within the not-for-profit charitable organization iMERiT, International Medical Education and Research Initiative, under Belgian law. The IFA website (http://www.fluidacademy.org ) is now an official SMACC affiliated site (Social Media and Critical (are) and its content is based on the philosophy of FOAM (Free Open Access Medical education — \#FOAMed). The site recently received the HONcode quality label for medical education (https://www.healthonnet.org/HONcode/Conduct.html?HONConduct519739). The other authors have no possible conflicts of interest in relation to the contents of this paper.

\section{References:}

1. Kirkpatrick AW, Roberts DJ, De Waele J, et al. Pediatric Guidelines Sub-Committee for the World Society of the Abdominal Compartment Syndrome. Intra-abdominal hypertension and the abdominal compartment syndrome: updated consensus definitions and clinical practice guidelines from the World Society of the Abdominal Compartment Syndrome. Intensive Care Med. 2013; 39(7): 1190-1206, doi: 10.1007/ s00134-013-2906-z, indexed in Pubmed: 23673399.

2. Mahjoub Y, Plantefeve G. Cardiac ultrasound and abdominal compartment syndrome. Acta Clin Belg. 2007;62 Suppl 1:183-189, doi: 10.1179/ acb.2007.62.s1.024, indexed in Pubmed: 24881717.

3. Blaivas M. Ultrasound and abdominal compartment syndrome: can we cast the other tools aside yet? Crit Care Med. 2011; 39(2): 411-412, doi: 10.1378/chest.09-0502.

4. Al-Bahrani $A Z$, Abid GH, Sahgal E, et al. A prospective evaluation of $C T$ features predictive of intra-abdominal hypertension and abdominal compartment syndrome in critically ill surgical patients. Clin Radiol. 2007; 62(7): 676-682, doi: 10.1016/j.crad.2006.11.006, indexed in Pubmed: 17556037.

5. Pickhardt PJ, Shimony JS, Heiken JP, et al. The abdominal compartment syndrome: CT findings. AJR Am J Roentgenol. 1999; 173(3): 575-579, doi: 10.2214/ajr.173.3.10470882, indexed in Pubmed: 10470882

6. Patel A, Lall CG, Jennings SG, et al. Abdominal compartment syndrome. AJR Am J Roentgenol. 2007; 189(5): 1037-1043, doi: 10.2214/ AJR.07.2092, indexed in Pubmed: 17954637.

7. Epelman $M$, Soudack $M$, Engel $A$, et al. Abdominal compartment syndrome in children: CT findings. Pediatr Radiol. 2002; 32(5): 319-322, doi: 10.1007/s00247-001-0569-3, indexed in Pubmed: 11956717.

8. Wachsberg RH, Sebastiano LL, Levine CD. Narrowing of the upper abdominal inferior vena cava in patients with elevated intraabdominal pressure. Abdom Imaging. 1998; 23(1): 99-102, indexed in Pubmed: 9437074.

9. Sugrue M, Maier R. Emergency Surgery Performance, Quality and Outcome Consensus Summit-Resource for optimal care of emergency surgery. DCRA \& WSES, Donegal 2016.

10. Alshamari M, Norrman E, Geijer M, et al. Diagnostic accuracy of low-dose $\mathrm{CT}$ compared with abdominal radiography in non-traumatic acute abdominal pain: prospective study and systematic review. Eur Radiol. 2016; 26(6): 1766-1774, doi: 10.1007/s00330-015-3984-9, indexed in Pubmed: 26385800

11. Sugrue M, Connolly M. Mistakes in the open abdomen. In: Coccolini F, Ivatury R, Sugrue M, Ansaloni L. ed. Manual open abdomen. Springer in press.
12. Sugrue M. Abdominal compartment syndrome and the open abdomen: any unresolved issues? Curr Opin Crit Care. 2017; 23(1): 73-78, doi: 10.1097/MCC.0000000000000371, indexed in Pubmed: 27941356

13. Soto JA, Anderson SW. Multidetector CT of blunt abdominal trauma. Radiology. 2012; 265(3): 678-693, doi: 10.1148/radiol.12120354, indexed in Pubmed: 23175542.

14. Diebel LN, Dulchavsky SA, Wilson RF. Effect of increased intra-abdominal pressure on mesenteric arterial and intestinal mucosal blood flow. J Trauma Acute Care Surg . 1992; 33(1): 45-49.

15. Roberts D, Waele JDe, Kirkpatrick A, et al. Intra-Abdominal hypertension and the abdominal compartment syndrome. Surgical Intensive Care Medicine. 2016: 621-644, doi: 10.1007/978-3-319-19668-8_46.

16. Diebel L, Dulchavsky S, Wilson R. Effect of increased intra-abdomina pressure on mesenteric arterial and intestinal mucosal blood flow. J Trauma Acute Care Surg. 1992; 33(1): 45-49, doi: 10.1097/00005373199207000-00010.

17. Diebel L, Wilson R, Dulchavsky S, et al. Effect of increased intra-abdominal pressure on hepatic arterial, portal venous, and hepatic microcirculatory blood flow. J Trauma Acute Care Surg. 1992; 33(2): 279-283, doi: 10.1097/00005373-199208000-00019.

18. Kaussen T, Srinivasan PK, Afify M, et al. Influence of two different levels of intra-abdominal hypertension on bacterial translocation in a porcine model. Ann Intensive Care. 2012; 2 Suppl 1: S17, doi: 10.1186/21105820-2-S1-S17, indexed in Pubmed: 22873417.

19. Malbrain ML, De Laet I. AIDS is coming to your ICU: be prepared for acute bowel injury and acute intestinal distress syndrome... Intensive Care Med. 2008; 34(9): 1565-1569, doi: 10.1007/s00134-008-1135-3, indexed in Pubmed: 18446318.

20. Mertens zur Borg IR, Verbrugge SJ, Olvera Cl. Intra-abdominal hypertension and the respiratory system. Abdominal Compartment Syndrome. Landis Bioscience, Georgetown 2006: 105-18.

21. Woodring JH, Reed JC. Types and mechanisms of pulmonary atelectasis. J Thorac Imaging. 1996; 11(2): 92-108, indexed in Pubmed: 8820021.

22. Quintel $\mathrm{M}$, Pelosi $\mathrm{P}$, Caironi $\mathrm{P}$, et al. An increase of abdominal pressure increases pulmonary edema in oleic acid-induced lung injury. Am J Respir Crit Care Med. 2004; 169(4):534-541, doi: 10.1164/rccm.200209-10600C, indexed in Pubmed: 14670801.

23. Gluecker T, Capasso P, Schnyder P, et al. Clinical and radiologic features of pulmonary edema. Radiographics. 1999; 19(6): 1507-31; discussion 1532, doi: 10.1148/radiographics.19.6.g99no211507, indexed in Pubmed: 10555672.

24. Quintel $M$, Pelosi $P$, Caironi $P$, et al. An increase of abdominal pressure increases pulmonary edema in oleic acid-induced lung injury. Am J Respir Crit Care Med. 2004; 169(4):534-541, doi: 10.1164/rccm.200209-10600C, indexed in Pubmed: 14670801.

25. Gluecker T, Capasso P, Schnyder P, et al. Clinical and radiologic features of pulmonary edema. Radiographics. 1999; 19(6): 1507-1531; discussion 1532, doi: 10.1148/radiographics.19.6.g99no211507, indexed in Pubmed: 10555672.

26. Mohmand H, Goldfarb S. Renal dysfunction associated with intra-abdominal hypertension and the abdominal compartment syndrome. J Am Soc Nephrol. 2011; 22(4): 615-621, doi: 10.1681/ASN.2010121222, indexed in Pubmed: 21310818.

27. Umgelter A, ReindI W, Franzen $M$, et al. Renal resistive index and renal function before and after paracentesis in patients with hepatorenal syndrome and tense ascites. Intensive Care Med. 2009; 35(1): 152-156, doi: 10.1007/s00134-008-1253-y, indexed in Pubmed: 18802688.

28. Bloomfield GL, Ridings PC, Blocher CR, et al. A proposed relationship between increased intra-abdominal, intrathoracic, and intracranial pressure. Crit Care Med. 1997; 25(3): 496-503, indexed in Pubmed: 9118668.

29. Hoeffner EG, Case I, Jain R, et al. Cerebral perfusion CT: technique and clinical applications. Radiology. 2004; 231(3): 632-644, doi: 10.1148/ radiol.2313021488, indexed in Pubmed: 15118110.

30. Malbrain ML, Peeters Y, Wise R. The neglected role of abdominal compliance in organ-organ interactions. Crit Care. 2016; 20:67, doi: 10.1186/ s13054-016-1220-x, indexed in Pubmed: 26983963.

31. Nemoto $M$, Yeernuer $T$, Masutani $Y$, et al. Development of automatic visceral fat volume calculation software for CT volume data. J Obes. 2014; 2014: 495084, doi: 10.1155/2014/495084, indexed in Pubmed: 24782922.

32. Malbrain ML, De Laet I, De Waele JJ, et al. The role of abdominal compliance, the neglected parameter in critically ill patients - a consensus review of 16. Part 2: measurement techniques and management 
recommendations. Anaesthesiol Intensive Ther. 2014; 46(5): 406-432, doi: 10.5603/AIT.2014.0063, indexed in Pubmed: 25432559.

33. Sugerman $\mathrm{H}$, Windsor $\mathrm{A}$, Bessos $\mathrm{M}$, et al. Intra-abdominal pressure, sagittal abdominal diameter and obesity comorbidity. J Intern Med. 1997; 241(1): 71-79, indexed in Pubmed: 9042096.

34. De Keulenaer BL, De Waele JJ, Powell B, et al. What is normal intra-abdominal pressure and how is it affected by positioning, body mass and positive end-expiratory pressure? Intensive Care Med. 2009; 35(6): 969-976, doi: 10.1007/s00134-009-1445-0, indexed in Pubmed: 19242675.

35. Mulier J, Coenegrachts K, Moortele KV. CT analysis of the elastic deformation and elongation of the abdominal wall during colon inflation for virtual coloscopy. Eur J Anaesthesiol. 2008; 25(Sup 44): 42, doi: 10.1097/00003643-200805001-00132.

36. Villoria A, Azpiroz F, Soldevilla A, et al. Abdominal accommodation: a coordinated adaptation of the abdominal wall to its content. Am J Gastroenterol. 2008; 103(11): 2807-2815, doi: 10.1111/j.1572-0241.2008.02141.x, indexed in Pubmed: 18786126.

37. Zhou Jc, Xu Qp, Pan Kh, et al. Effect of increased intra-abdominal pressure and decompressive laparotomy on aerated lung volume distribution. J Zhejiang Univ Sci B. 2010; 11(5): 378-385, doi: 10.1631/ jzus.B0900270, indexed in Pubmed: 20443216.

38. Severgnini $P$, Inzigneri $G$, Olvera $C$, et al. New and old tools for abdominal imaging in critically ill patients. Acta Clin Belg. 2007; 62 Suppl 1: 173182, doi: 10.1179/acb.2007.62.s1.023, indexed in Pubmed: 24881716.

39. Cheatham ML, Safcsak K. Percutaneous catheter decompression in the treatment of elevated intraabdominal pressure. Chest. 2011; 140(6): 1428-1435, doi: 10.1378/chest.10-2789, indexed in Pubmed: 21903735.

40. Sugrue M. Open abdomen strategies in acute care surgery: When and how. In: Di Saverio S, Catena F, Ansaloni L, Coccolini F, Velmahos G. ed. Acute care surgery handbook. Two-volume. Springer International Publishing 2016.

41. Parmentier-Decrucq E, Poissy J, Favory R, et al. Adverse events during intrahospital transport of critically ill patients: incidence and risk factors. Ann Intensive Care. 2013; 3(1): 10, doi: 10.1186/2110-5820-3-10, indexed in Pubmed: 23587445.

42. Smith-Bindman R, Lipson J, Marcus R, et al. Radiation dose associated with common computed tomography examinations and the associated lifetime attributable risk of cancer. Arch Intern Med. 2009; 169(22): 2078-2086, doi: 10.1001/archinternmed.2009.427, indexed in Pubmed: 20008690.

43. Mitchell $\mathrm{AM}$, Jones $\mathrm{AE}$, Tumlin JA, et al. Incidence of contrast-induced nephropathy after contrast-enhanced computed tomography in the outpatient setting. Clin J Am Soc Nephrol. 2010; 5(1): 4-9, doi: 10.2215/ CJN.05200709, indexed in Pubmed: 19965528.

44. Hinson JS, Ehmann MR, Fine DM, et al. Risk of Acute Kidney Injury After Intravenous Contrast Media Administration. Ann Emerg Med. 2017; 69(5): 577-586.e4, doi: 10.1016/j.annemergmed.2016.11.021, indexed in Pubmed: 28131489.

45. De Waele JJ, Hoste EAj, Malbrain ML. Decompressive laparotomy for abdominal compartment syndrome - a critical analysis. Crit Care. 2006; 10(2): R51, doi: 10.1186/cc4870, indexed in Pubmed: 16569255.

46. Peter SD, Abbas MA, Kelly KA. The spectrum of pneumatosis intestinalis. Arch Surg. 2003; 138(1): 68-75, indexed in Pubmed: 12511155.

47. Umapathi BA, Friel CM, Stukenborg GJ, et al. Estimating the risk of bowel ischemia requiring surgery in patients with tomographic evidence of pneumatosis intestinalis. Am J Surg. 2016; 212(4): 762-768, doi: 10.1016/j.amjsurg.2015.09.010, indexed in Pubmed: 26721198.
48. Amorosa JK, Bramwit MP, Mohammed TLH, et al. ACR appropriateness criteria routine chest radiographs in intensive care unit patients. J Am Coll Radiol. 2013; 10(3): 170-174, doi: 10.1016/j.jacr.2012.11.013, indexed in Pubmed: 23571057.

49. Oba Y, Zaza T. Abandoning daily routine chest radiography in the intensive care unit: meta-analysis. Radiology. 2010; 255(2): 386-395, doi: 10.1148/radiol.10090946, indexed in Pubmed: 20413752.

50. Ferguson ND, Fan E, Camporota $L$, et al. The Berlin definition of ARDS an expanded rationale, justification, and supplementary material. Intensive Care Med. 2012; 38(10): 1573-1582, doi: 10.1007/s00134012-2682-1, indexed in Pubmed: 22926653.

51. Alder AC, Hunt JL, Thal ER. Abdominal compartment syndrome associated with tension pneumoperitoneum in an elderly trauma patient. J Trauma. 2008; 64(1): 211-212, doi: 10.1097/TA.0b013e3180342077, indexed in Pubmed: 18188123.

52. Ali SZ, Freeman BD, Coopersmith CM. Abdominal compartment syndrome in a patient resulting from pneumothorax. Intensive Care Med. 2003; 29(9): 1614, doi: 10.1007/s00134-003-1903-z, indexed in Pubmed: 12879231.

53. García-Santos E, Puerto-Puerto A, Sánchez-García S, et al. Abdominal compartment syndrome by tension pneumoperitoneum secondary to barotrauma. Presentation case. Cirugía y Cirujanos (English Edition). 2015; 83(5): 429-432, doi: 10.1016/j.circen.2015.10.014.

54. Paulson EK, Thompson WM. Review of small-bowel obstruction: the diagnosis and when to worry. Radiology. 2015; 275(2): 332-342, doi: 10.1148/radiol.15131519, indexed in Pubmed: 25906301.

55. Jaffe T, Thompson WM. Large-bowel obstruction in the adult: classic radiographic and ct findings, etiology, and mimics. Radiology. 2015; 275(3): 651-663, doi: 10.1148/radiol.2015140916, indexed in Pubmed: 25997131.

56. Frager D. Intestinal obstruction role of CT. Gastroenterol Clin North Am. 2002; 31(3): 777-799, indexed in Pubmed: 12481731.

57. De Backer D, Creteur J, Preiser JC, et al. Microvascular blood flow is altered in patients with sepsis. Am J Respir Crit Care Med. 2002; 166(1): 98-104.

58. De Backer D, Durand A. Monitoring the microcirculation in critically ill patients. Best Pract Res Clin Anaesthesiol. 2014; 28(4): 441-451, doi: 10.1016/j.bpa.2014.09.005, indexed in Pubmed: 25480773.

59. Massey MJ, Shapiro NI. A guide to human in vivo microcirculatory flow image analysis. Crit Care. 2016; 20:35, doi: 10.1186/s13054-016-1213-9, indexed in Pubmed: 26861691.

60. De Backer D, Hollenberg S, Boerma C, et al. How to evaluate the microcirculation: report of a round table conference. Crit Care. 2007; 11(5): R101, doi: 10.1186/cc6118, indexed in Pubmed: 17845716.

61. Carlson AP, Yonas H. Portable head computed tomography scanner - technology and applications: experience with 3421 scans. J Neuroimaging. 2012; 22(4):408-415, doi: 10.1111/j.1552-6569.2011.00621.x, indexed in Pubmed: 21699615.

\section{Corresponding author:}

Gavin Sugrue

Department of Radiology Mater Misericordiae University Hospital,

Dublin, Ireland

e-mail:g_sugrue@hotmail.com

Received: 1.10.2017

Accepted: 13.11.2017r. 